\title{
SABERES TRADICIONAIS TUPI: ESTAR JUNTO, APRENDER, NHEMBOJERA
}

\author{
Ana Paula da Silval (D)
}

\begin{abstract}
RESUMO: O presente artigo buscou refletir sobre a dinâmica própria da transmissáo de saberes e práticas tradicionais dos chamados tupi, registrados por cronistas franceses entre os séculos XVI e XVII, valorizando concepçóes indígenas relacionadas à biodiversidade. Para tanto, analisei algumas categorias classificatórias a respeito de plantas e animais que nos permitem discutir parte do sistema taxonômico e o modo como povos falantes da língua tupinambá nomeavam o que chamamos de natureza.
\end{abstract}

Palavras-chave: Educação indígena. Saberes indígenas. Oralidade. Taxonomia tupi.

\section{Traditional tupi knowledge: being together, learning, nhembojera}

ABSTRACT: The article tries to reflect on the dynamics of the transmission of traditional knowledge and practices of the Tupi, recorded by French chroniclers between the sixteenth and seventeenth centuries, valuing indigenous conceptions related to biodiversity. To this end, some classificatory categories regarding plants and animals were analyzed, allowing for the discussion of part of the taxonomic system and the way people speaking the Tupinambá language knew.

Keywords: Indigenous education. Indigenous knowledge. Orality. Tupi taxonomy.

${ }^{1}$ Universidade do Estado do Rio de Janeiro - Rio de Janeiro (RJ), Brasil. E-mail: anapproindio@gmail.com

DOI: 10.1590/CC0101-32622019216679 


\section{INTRODUÇÃO}

Há 10 anos, em março de 2008, promulgava-se a Lei $n^{\circ}$ 11.645 (BRASIL, 2008), com o objetivo de incluir no currículo oficial da rede de ensino a obrigatoriedade da temática cultura e história indígena. De modo geral, parte da população brasileira, incluindo milhares de estudantes (em todos os níveis de ensino), desconhecia a diversidade sociocultural e linguística dos povos originários habitantes no país. Sabia-se muito pouco e, desde então, variadas açóes foram desenvolvidas para qualificar o ensino e difundir informaçôes a respeito dessas sociedades. Todavia, a julgar pelos inúmeros episódios de violência, descaso, racismo e perseguição aos indígenas (constantemente atualizados desde 1500 até os dias atuais), necessita-se, entre outros aspectos, discutir a qualidade do ensino-aprendizagem e investir em pesquisas, porque, "se nós não tivermos um conhecimento correto sobre a história indígena, sobre o que aconteceu na relação com os índios, não poderemos explicar o Brasil contemporâneo", enfatiza José Bessa Freire (2016, p. 3).

Nesse sentido, este artigo $^{1}$ é um convite à reflexão sobre a importância dos povos indígenas (especialmente os antigos tupi, ou apenas tupi ${ }^{2}$ ) e seus saberes tradicionais para a nossa história, para a educação e para a diversidade sociocultural e linguística do país. Recorrerei, assim, às informaçóes registradas por cronistas franceses nos séculos XVI e XVII — André Thevet (2009), Jean de Léry (2009), Claude d'Abbeville (1975) e Yves D’Évreux (2009) (publicada somente em 1864) —, realizando o cotejo com estudos histórico-antropológicos e linguísticos já clássicos, sobretudo Florestan Fernandes (1976), padre Lemos Barbosa (1956), além de pesquisas atuais acerca de formas de conhecer dos povos indígenas, com olhar particular para a investigação de Joana de Oliveira (2012) - todos fundamentais na escrita do presente texto.

\section{ESTAR JUNTO, APRENDER}

Para os guarani do Rio de Janeiro, o que denominamos de conhecimento tradicional pode ser traduzido como Mbya arandu. ${ }^{3}$. Mbya é a autodeterminação, e arandu, seus saberes e práticas. Ou seja, trata-se 
de todo o conhecimento guardado na mente - ijeyvateve kuery arandu (literalmente, nossa sabedoria). Nesse contexto, Mbya arandu pode ser entendido como patrimônio intangível/imaterial, e sua dimensão material aproxima-se da categoria nhembojera (abrir-se em flor), tendo em vista que esses saberes se concretizam, se transformam, por exemplo, em cada ato de plantar uma semente de avati (milho), batizada para uma colheita farta com as técnicas necessárias de plantio, incluindo as rezas/ os cantos proferidos na abertura da covinha. De igual modo, podemos utilizar o conceito de nhembojera em cada gesto de entrelaçar a taquara na confecção de cestos.

A farta colheita, bem-sucedida, e a feitura de um belo ajaka (cesto) são a materialização daquilo que está na cabeça, a transformação do intangível no material, é nhembojera. São os patrimônios em movimento. Penso ser essa imagem-potência uma boa forma de iniciar este artigo, evidenciando a poética e a sofisticação das categorias e dos saberes indígenas, reveladas especialmente em seus sistemas de classificaçóes.

Para Lévi-Strauss (1962), os indígenas observam a natureza, experimentam, criam hipóteses e testam. Eles possuem conhecimentos profundos sobre o que chamamos de natureza, tais como: técnicas de plantio e de caçada (que incluem o conhecimento dos sons - grunhidos, assobios, gritos - tipos de fezes, garras e pegadas dos animais), formas de descrição da vegetação e de classificação de espécies, dos solos, das paisagens, entre outros. Para diversos povos originários no Brasil, o aprendizado está no acompanhar, no estar junto (conviver), no observar, no imitar e no praticar determinado saber. É o caso, por exemplo, dos huni kuin (também conhecidos como kaxinawá), conforme explica Ingrid Weber (2006) ao analisar a forma de transmissão dos desenhos kene e da tecelagem. A antropóloga afirma que para eles a aquisiçáo de uma habilidade está diretamente ligada ao convívio, "já que é nesse espaço-tempo de observação, de imitaçáo e de prática que o aprendizado se dá" (WEBER, 2006, p. 197). Trata-se de um aprendizado "sem palavras", como caracterizou Weber (2006).

Joana de Oliveira (2012), de igual modo, descreveu a dinâmica de observação, de participação e de treino prático entre os wajāpi, enfatizando a relevância do estar junto como forma de transmissão de saberes - processo que implica observaçáo, aconselhamento, enuncia- 
ção, silêncio e prática conjunta nas realizações de tarefas. "O saber é, portanto, gradualmente ensinado ao mesmo tempo em que é realizado e vivido" (OLIVEIRA, 2012, p. 174). Algo semelhante pode ser visto em Marangmotxíngmo Mïrang - Das crianças Ikpeng para o mundo, uma resposta ao vídeo-carta enviado por crianças de Sierra Maestra (Cuba). De modo peculiar, os ikpeng apresentam o dia a dia na aldeia, suas famílias, brincadeiras, artefatos, comidas, festas. Entre um sorriso e outro, juntos, meninas de um lado, meninos de outro, apresentam a sua paisagem do brincar, convidando os espectadores para uma mirada particular, livre e espontânea do ser criança ikpeng.

Aprender junto e sem palavras são parte da dinâmica de conhecer algo para diferentes povos indígenas. O lúdico entre as kyringue (crianças) guarani está nas nheovanga (brincadeiras); elas aprendem onhevágaa rupi onhembo'e - literalmente, "brincando, praticando e aprendendo" (BENITES, 2015, p. 22). Sandra Benites (2015, p. 17), professora guarani, explica que não se trata de "simples brincadeiras", pois elas têm "função de ensinar, de ser feliz. Sáo momentos de alegria para as crianças, de compartilhar, de brincar, de conhecer/escutar, de respeitar o outro". A criança guarani aprende acompanhando e observando os mais velhos jovens ou adultos - na roça, nas atividades de caça e de pesca, durante a confecção dos artefatos de arte, no dia a dia em seu tekoa (aqui traduzido como aldeia). "É importante ouvir, observar como os mais velhos se comportam, agem. Isso vale para a pesca, a caça, a plantação, para tudo", salienta Sandra Benites (2015, p. 23) ao refletir sobre a infância guarani e o processo de aprendizado das kyringue do arandu (conhecimento) e das normas do nhandereko (jeito de ser e viver).

Florestan Fernandes (1976) constatou procedimento análogo na documentaçáo histórica sobre os povos indígenas, falantes da língua tupinambá, nos primeiros séculos de colonização. Para o sociólogo, na dinâmica do aprendizado dos antigos tupi, a máxima da filosofia educacional era o "aprender fazendo", algo como "é katu resê" - "saber fazer" (LEMOS BARBOSA, 1956, p. 184). Estimulados e envolvidos pelos adultos nas atividades cotidianas, crianças e jovens aprendiam imitando, de acordo com a divisão de trabalho por sexo e idade (FERNANDES, 1976). Nesse processo de aprendizado, Fernandes (1976) destaca o papel da guaimĩ (velha) e do tuibaé (velho) na transmissão dos conhecimen- 
tos tupi. As guaimĩ eram responsáveis por todo o trabalho doméstico, além de fabricar o cauim (bebida fermentada feita de mandioca, milho ou frutas), carpir os mortos, recepcionar os atuasaba (aliados, sócios, compadres) nas aldeias, preparar o repasto antropofágico, dividir a caça, orientar as neófitas, preparar diversas reunióes. Os tuibaé chefiavam as nhomonoongaba (reuniōes) nas casas-grandes ${ }^{4}$, as caçadas, as pescarias, as guerras. Com relação aos espaços de transmissão de saberes, D’Évreux (2009) descreve os lugares onde os mais velhos gostavam de falar sobre os seus tamỹi pagũama (antepassados):

Eles fazem isso em suas casas de reunióes, e algumas vezes em suas malocas, levantando-se de manhã cedo e excitando os seus a escutarem os discursos. O mesmo eles fazem quando se visitam, pois se abraçam, e chorando de ternura, repetem um após o outro, palavra por palavra, os nomes de seus avós e antepassados e tudo o que se passou em seus séculos (D'ÉVREUX, 2009, p. 165).

A tava (aldeia), de modo geral, era um lugar de referência importante para a difusão dos saberes e do jeito de ser e viver dos tupi. Todavia, existiam ali lugares outros, específicos, como a casa dos homens ou o local de reclusão das moças, igualmente fundamentais na dinâmica do aprendizado. Os tuibaé e as guaimĩ detinham saberes específicos de sua cultura, conheciam os espaços próprios de transmissão e sabiam o momento mais adequado para transmiti-los aos mais jovens.

Acredito que a dinâmica do aprendizado dos antigos tupi está longe de ser um "adestramento" dos iniciados, conforme propôs Florestan Fernandes (1976, p. 73). Seria mais interessante pensar nos termos que propóe Joana de Oliveira (2012) ao inverter a expressão "saber fazer". Para a autora, a inversão "fazer saber" enfatiza a existência dos saberes quando são efetivados no curso de uma vida: "Os saberes não existem, pois fora de uma execuçâo e entendo aqui execução como todas as formas de expressão de um saber e não exclusivamente a dimensão pragmática" (OLIVEIRA, 2012, p. 162). A autora ressalta que o cultivo de uma planta, por exemplo, requer o domínio de técnicas (escolha do solo, da 
época de plantio, da profundidade da cova etc.) e das palavras/dos cantos necessários para que ela brote vigorosa. Aprendem-se o nome, a história, as propriedades gustativas e saberes outros associados às plantas.

Para atingir o nível de especialização descrito por Joana de Oliveira (2012), é preciso que esses saberes sejam transmitidos desde a infância, por meio do estar junto, da observação, da dedicação e da repetição de tarefas realizadas em diferentes situaçóes - cotidiano, rituais, festas, reunióes, entre outros. Assim, adultos poderão se tornar especialistas. Informaçóes dessa natureza lamentavelmente são incipientes na documentação histórica dos primeiros séculos de conquista, tendo em vista que os chamados patrimônios imateriais não constituíam um tema potencial para os cronistas, como a antropofagia, a nudez, a poliginia e a natureza. Se não podemos aqui desenvolver uma minuciosa reflexão sobre o processo de especialização das formas de construção dos saberes nem acerca do refinamento dos seus processos para os tupi (no que tange às classificaçôes da flora e da fauna), é possível, contudo, tecer consideraçóes mais pontuais sobre as formas de nomeá-los, recorrendo para isso às nomenclaturas tupi registradas por Thevet (2009), Léry (2009), D'Abbeville (1975) e D’Évreux (2009). É o que faremos na segunda parte deste artigo.

\section{NO MUNDO DO SENSÍVEL}

Após apresentar breves considerações sobre a transmissão e o compartilhamento de saberes indígenas, refletiremos acerca do modo como os antigos tupi conheciam o que chamamos de natureza. Vale destacar que o processo de restauro das informaçóes linguísticas, realizado com o imprescindível apoio da uaraúna Ruth Monserrat (2017), foi fundamental para desenvolver as questóes aqui suscitadas a respeito do sistema de classificação tupi.

Na língua tupinambá não existem categorias abrangentes correspondentes ao que traduzimos por animal, planta, vegetal. Existem, conforme Lemos Barbosa (1956), as categorias soó (animais de caça) e kaá (mato, mata, planta) — a atribuição do sentido depende do contexto em questão. Encontramos categorias abrangentes para árvores madeiras, 
paus (ybirá ou $y b a)$, peixes (pirá), pássaros $(g u y r a ̂)$, fruto/fruta $(y b a ̂)$. Há casos, no entanto, em que a categoria classifica espécies diferentes. Por exemplo, o termo guará é empregado tanto para designar uma espécie de ave, o guará (Eudocimus ruber), quanto o lobo-guará (Chrysocyon brachyurus), uma espécie de canídeo endêmico da América do Sul. O padre D’Abbeville (1975), por sua vez, menciona uma espécie de peixe marinho, o guará guaçu, com igual denominação.

Por outro lado, comparando o sistema tupi com o científico, percebemos que certas categorias taxonômicas indígenas identificam espécies diferentes, geralmente pertencentes à mesma família. Citamos, entre os outros exemplos possíveis, o tatu (mamífero), acaiúlacaijú (caju), acará (acará, cará) peixe, caí (macaco), nambú (nambu, inhambú) ave. Nas fontes há o registro dos seguintes tipos de tatu: tatu peba (tatu-peba); tatú-apár (tatu-apara ou tatu-bola), tatú-i-guaçú e tatú-eté-mirĩ.

João Barbosa Rodrigues (1992), no artigo "Mbaé Kaá", versa acerca da classificação botânica indígena, destacando o refinamento e a sofisticação desses saberes. Ele constatou que a nomenclatura parecia, “à primeira vista, termos de difícil pronúncia, de uma língua bárbara, contudo, são tão bárbaros como os que a ciência emprega, tirados das línguas clássicas e mortas” (BARBOSA RODRIGUES, 1992, p. 19). Exemplificando, o naturalista brasileiro comparou, entre outros, a classificação genérica dos solidagos feita por indígenas e as nomenclaturas propostas por "homens de sciencia e autores", destacando que Mbuyboty ybámi $i^{5}$, "espiga de flores pequenas côr de ouro" (BARBOSA RODRIGUES, 1992, p. 19), é mais descritiva do que Solidago foliis ovatis serratis, proposta pelo botânico Nikolaus Jacquin, que específica apenas a forma da folha, ou mesmo "Virga aurea" (espiga de ouro), como classifica o botânico francês Joseph de Tournefort (BARBOSA RODRIGUES, 1992, p. 38-39).

Se a classificação proposta por João Barbosa Rodrigues (1992) é entendida como pragmática e ideológica (FERREIRA; NOELLI, 2009); por outro lado, cabe destacar a grande relevância de seu trabalho e a sua tentativa de chamar a atenção, na época, da comunidade científica para os saberes e as práticas indígenas. No século XIX, o naturalista reconheceu e valorizou, como poucos, principalmente o conhecimento dos povos indígenas associados à natureza (SÁ, 2001, p. 912), fruto das 
observaçóes e conversas com indígenas, especialmente Maximiano José Roberto (índio descendente dos manaus, pelo lado paterno, e dos tarianas do rio Uaupés, pelo materno). Os dois conheceram-se em 1872, quando Barbosa Rodrigues viajou para Manaus, e juntos exploraram a região do Baixo Amazonas, anotando informaçóes importantes dos usos que os povos faziam da flora local na medicina, na culinária e na habitação. Ali "aprendeu o nheengatu e coletou narrativas orais, contos e cantigas nessa língua, publicadas no Poranduba amazonense”, conforme explica Freire (2004, p. 144-145).

É interessante notar que, ao discutir aspectos da classificação botânica de falantes do nheengatu, Barbosa Rodrigues (1992) enfatizou as mesmas características que o antropólogo francês Claude Lévi-Strauss (1962), anos mais tarde, destacaria e conceituaria como a "lógica do sensível”. Barbosa Rodrigues (1992, p. 9, grifos meus) escreveu:

Pelo fructo de suas observaçóes, seguiam (indígenas) um methodo synthetico na classificação das plantas. Designam as espécies por nomes tirados dos caracteres das folhas, das flores, dos fructos, ou de propriedades como o cheiro, o sabor, a dureza, a duração, a cor, o emprego, etc.

Joana de Oliveira (2012, p. 43), de igual modo, ressalta as categorias sensíveis nas formas classificatórias dos wajâpi, discutindo a maneira como eles conhecem a floresta. Para a autora, os aspectos notados pelos wajāpi ultrapassam os meros traços morfológicos, incorporando cheiros, gostos, texturas e modos de enunciação. Procedimento análogo evidenciamos na classificação dos tupi, povos também falantes de uma língua pertencente à família linguística tupi-guarani. Na maioria dos nomes da botânica e da zoologia registrados pelos cronistas franceses, encontramos uma categoria substantiva seguida de um sufixo qualificativo relacionado ao tamanho, à cor, ao gosto, à forma e à consistência. Os sufixos indicadores de comprimento mais comuns são: guaçu (grande), mirĩlmiri (pequeno) e puku (longo, comprido) - guryrá guaçu (pássaro grande), pirá mirĩ ou pirá-i (peixe pequeno/peixinho), ybyráý puku (árvore de tronco longo). Segundo o padre Lemos Barbosa (1956, p. 63), com a mesma acepção existem (t)ayri e (t)isii (pequeno, miúdo). Já para 
designar a altura, empregava-se ybaté (alto, em cima, no alto), que era usado como substantivo e adjetivo (LEMOS BARBOSA, 1956). Não verificamos, todavia, o registro desses três últimos sufixos na documentação pesquisada.

Com relação ao sistema de cores, empregavam as categorias: iúbaluar (amarelo), úna (preto), pitang/pitanga (vermelho), oby (verde, azul), tíng ou tinga (branco), kuatiára (desenhos, riscos), péma (trançado) e pinilpinima (salpicados de pintas, pontos). Seguem alguns exemplos: guyrá uar (pássaro amarelo), guarajuba (Conurus guarouba), guyrá guaçu-pinĩ (pássaro grande, salpicado de pintas ou pontos), pirá kuatiára (peixe pintado, desenhado, lavrado) e ybýra pytáng (árvore vermelha), o pau-brasil (Caesalpinia echinata).

$\mathrm{Na}$ taxonomia tupi, como temos visto, é recorrente nomear baseando-se na morfologia dos vegetais e animais. É o caso da $y b a-p i-$ rúba (árvore espinhosa), ýba-membéka (árvore mole), dos sufixos upaba (largo), péblpéba (chato), ẽe (doce/salgado) e ypoxí (ruim, feio, nojento). Desse modo, tem-se os exemplos: ybýra eẽ (espécie de árvore que tem gosto doce ou salgado), y e ẽ (água salgada, do mar), ybá ee (fruta doce), pirá ẽ̃ (peixe salgado), acará péba (designação comum a vários peixes da família Cichlidae), acará ou cará chato, pirá ypoxý (espécie de peixe não apreciado para o consumo, ruim).

Outros sufixos que aparecem nas crônicas são o eté e o rana, sendo o primeiro o oposto do segundo. O eté combinado a um substantivo assume o sentido de valor, preciosidade, genuinidade e grandeza (LEMOS BARBOSA, 1956, p. 82). Por essa razão, é comum traduzi-lo como verdadeiro. Na designação jaguar, por exemplo, acrescentou-se o sufixo eté para diferenciar a onça (jaguar eté) do cão, normalmente qualificado como jaguar. Nesse caso, isso ocorreu porque objetos e animais trazidos por europeus foram nomeados com base em artefatos e seres conhecidos dos indígenas. Era necessário, portanto, diferenciá-los; na opinião de Lemos Barbosa (1956, p. 386), "voltar ao primitivo sentido”. De igual modo, verificamos y-eté (água boa, oposto de salgada, suja, ruim) e uuba-rãna (flecha mal feita, tosca).

Já o sufixo rana significa "semelhante, parecido, pseudo - o que parece, mas não é igual”. Por isso, o padre Lemos Barbosa (1956, p. 
83) atribuiu o sentido de "mal feito, tosco, grosseiro". A tradução mais recorrente é falso - janypába-rãna (o que parece jenipapo, mas não é). Joana de Oliveira (2012, p. 59) diz que o sufixo rãna ("o que parece ser não sendo") é constante na composição wajāpi de nomes de espécies da floresta e constitui outra maneira de estabelecer uma relação sensível entre plantas. Assim, a autora considera esse sufixo um "coringa", em razão da possibilidade de combiná-lo a nomes conhecidos da taxonomia wajãpi para classificar os vegetais desconhecidos, não existentes na mata, roças ou pátios. Nesse sentido, o sufixo räna permite criar nomes, novas categorias (OLIVEIRA, 2012, p. 59).

Nessa discussão, cabe destacar um tipo particular de nomenclatura que chamou a minha atenção. Trata-se das categorias japi-ýba, em que japi = japim (pássaro) e ýba (árvore). Logo, árvore do japim, além de guainumbý acaju = guainumbý (beija-flor) e acaju (caju). Assim, caju do beija-flor (uma traduçáo possível). Não sabemos os contextos do uso dessas categorias, todavia Barbosa Rodrigues (1992) dá-nos uma pista. Para o naturalista, esse tipo de classificação exprimia a ideia de referência. No processo de classificação wajápi de plantas, Joana de Oliveira (2012) menciona a importância do tamanho como referência recorrente na qualificação dos vegetais. Além dos qualificadores mais comuns, há também as qualidades sensíveis de animais como a anta (força, tamanho) e as espécies qualificadas com o sufixo rovijä (chefe), árvores proeminentes na floresta, relevantes no pensamento wajāpi. O referencial, portanto, é uma dimensão importante no processo de classificação indígena. Voltando às categorias tupi, as aves japi-ýba e guainumbý caju poderiam, por exemplo, se alimentar dos frutos e fazer ninhos em determinadas espécies de árvores e esse poderia ser um critério observado para nomeá-las.

Pude constatar, em 2015, análoga classificação entre os guarani do tekoa (território) Sapukai, localizado no município de Angra dos Reis (RJ). Trata-se da erva do karão (Aramus uaraúna), ave também conhecida como saracurão (SIMÕES, 2010, p. 119). Na ontologia guarani, o carão era um homem que encantou uma jovem solitária e triste com seu belo canto $^{6}$. Por isso, sua erva é utilizada com a finalidade de seduzir a pessoa amada (SILVA, 2013). São as chamadas káavo (ervas para conquistar ou erva do karão). As classificaçóes indígenas possuem lógicas distintas e seguem critérios diferentes dos nossos, inclusive explicaçóes cosmológicas. 
Vejamos a categoria kảaguy mirim, cuja classificação segue critérios ligados ao mundo dos espíritos/da ontologia guarani. Algemiro da Silva (2013) explica que na kảa (mata) existe kảaguy mirim, um lugar náo visível aos olhos dos jurua (não indígenas), intocável, pois é a morada de nhanderu mirim (demiurgo). Para os guarani, existem os nhanderu kuery (vários nhanderu), mas apenas nhanderu mirim mora na terra, em kảaguy mirim. É importante dizer que no contexto analisado mirim diz respeito ao plano do sagrado, diferenciando-se de pequeno, tradução mais recorrente. Ao questionar o professor indígena sobre a sua localização na mata, ele me respondeu que não existe um espaço preciso: "Está lá, nós sabemos onde e não podemos cortar as árvores, mexer em káaguy mirim” (SILVA, 2013, p. 21).

De igual modo, para os antigos tupi ka’a é o termo referente à mata, à floresta, à planta (LEMOS BARBOSA, 1956). Analogamente, Jean de Léry, no Colóquio entre as gentes do país (2009), traduziu ka'a como "toda a sorte de bosques e florestas", além de registrar um tipo específico de mata, ca'ápảu (entendido como bosque no meio de um campo), evidenciando a existência de diferentes formas de classificar a floresta, a paisagem. Lemos Barbosa (1956) distinguiu ao menos cinco tipos: kaá panema (mato sem caça), kaá apúá (mato redondo), kaá esákanga (mato ralo ou claro), kaá ikobé (planta viva) e kaá eté (mata virgem), ideia bastante questionável nos dias atuais (VIVEIROS DE CASTRO, 2011).

Léry (2009) documentou ainda categorias atribuídas segundo a relação dos seres que habitam a mata. Trata-se de ca'áyguán (ser que é alimentado pelos bosques) e do cảajára, "um espírito maligno". Îara ou jará, em tupinambá, aplica-se a senhor, dono (LEMOS BARBOSA, 1956, p. 52). Logo, cáájára significa dono da mata e jára me parece ter, nesse contexto, a mesma acepçáo do ija para os guarani (e outros povos falantes de línguas de igual parentesco). Algemiro da Silva (2013 e Sandra Benites (2015), em conversas frequentes, relatam que na natureza tudo têm ija. Por isso, não se pode entrar de qualquer jeito nos rios, cachoeiras e matas sem fazer reverência (pedir licença?) aos "donos" (como eles traduzem) desses lugares. Categoria análoga observou Joana de Oliveira (2012, p. 124) no universo wajápi. Para este, tudo tem -jarã (traduzido como "dono"), até mesmo a mata (káajarã = dono da mata).

No artigo "Donos demais: maestria e domínio na Amazônia", Carlos Fausto $(2008$, p. 329) discute a categoria indígena "dono" ou 
"maestria", bastante difundida entre os povos da Amazônia e "que transcende em muito a simples expressão de uma relação de propriedade ou domínio". Sintetizando a literatura etnográfica existente até então, o autor diz ser essa categoria ontológica um modo generalizado de relação e se caracteriza por interaçóes em diferentes esferas e entidades - humanos, animais, plantas, espíritos, artefatos. Entre os tupi-guarani, o antropólogo lembra que os termos para a categoria dono são cognatos de *jar e sáo conhecidos desde o século XVI.

A literatura histórico-antropológica vem documentando há séculos a intrínseca relação entre os povos indígenas, as entidades não humanas e seus territórios. Os tupinambá, atualmente habitantes no sul da Bahia, acreditam ser a Serra do Padeiro "a morada dos encantados" (ALARCON, 2013, p. 158). Os encantados ou caboclos são "entidades não humanas que possuem domínios territoriais específicos e têm capacidade de se deslocar, transmitir recados e mesmo 'baixar' em alguns indígenas" (ALARCON, 2015).

Para a antropóloga, no processo de retomada territorial desse povo os encantados têm papel central, incentivando os indígenas na luta por sua terra, ensinando estratégias e protegendo-os. Segundo Glicéria de Jesus da Silva ${ }^{7}$, liderança tupinambá da Serra do Padeiro, a relação que o seu povo mantém com a terra é bastante diferente da que nós (não indígenas) temos.

Glicéria Tupinambá, como é mais conhecida, explica que a recuperação da terra - em todos os sentidos — traz de volta animais, plantas e, consequentemente, os encantados, aliados e protetores, como o encantado do oti (maracujá selvagem). Dessa forma, a expropriação dos tupinambá de suas terras desapropria uma série de seres, os encantados (dos animais, plantas, pedras), tornando o lugar sem vida. Os territórios constituem elementos centrais nas formas de sobrevivência física e cultural dos povos indígenas, sendo fundamental para a preservação da biodiversidade brasileira.

$\mathrm{O}$ avanço das fronteiras agrícolas sobre as terras indígenas é uma marcha sobre o patrimônio ambiental do país, pois, conforme avalia Manuela Carneiro da Cunha (2009), os povos tradicionais têm papel crucial na conservação da agrobiodiversidade e suas práticas são de 
grande importância para a segurança alimentar. Para a antropóloga, é importante observar que, para além do caráter de universalidade da ciência, existem outros paradigmas de saber diferentes do nosso - com modos de conhecer a natureza, métodos, protocolos de investigação próprios. Os indígenas, portanto, tal como nós, ocidentais, produzem conhecimentos, porque "ambos são [ocidentais e indígenas] formas de procurar entender e agir sobre o mundo. Sáo obras abertas, inacabadas, se fazendo constantemente" (CARNEIRO DA CUNHA, 2009, p. 302).

Embora tenham direito à consulta prévia e decidir se querem ou não empreendimentos hidrelétricos, atividades mineradoras e madeireiras em seus territórios, os indígenas seguem ignorados pelo Estado. Todavia, guiados e inspirados por seres não humanos - ija, encantados, xapiripe - os povos indígenas criam variadas estratégias de luta para garantir seus territórios, suas vidas e seus conhecimentos.

\section{CONSIDERAÇÕES FINAIS: NHEMBOJERA}

Conforme as reflexóes propostas, relacionadas à apropriação e ao refinamento de saberes indígenas, torna-se evidente que na infância são transmitidos os conhecimentos mais básicos, fundamentais para futuras elaboraçóes complexas e para renovação e preservação dos saberes tradicionais de um povo. Nesse processo, a oralidade, a memória, especialmente a observação, as brincadeiras e caminhadas juntos aos parentes do ciclo familiar das crianças (pais, avós, tios, irmãos mais velhos), ou seja, o "estar junto", são fundamentais para que sejam consolidados diversos tipos de conhecimentos e para que as futuras geraçóes tenham acesso a esses conhecimentos.

É o que observamos nas informações disponíveis em fontes diversas, particularmente nas crônicas de Thevet (2009), Léry (2009), D'Abbeville (1975) e D'Évreux (2009) sobre os processos de ensino e aprendizagem dos tupi. Desde criança se aprende a manipular alimentos, as matérias-primas para construírem casas, objetos utilitários de uso cotidiano e ornamentos distintos empregados em rituais. Ainda pequenos, meninas e meninos igualmente aprendem os repertórios referentes à natureza - diferenciar espécies animais e vegetais e os seus ecossistemas 
pertencentes, conhecer os seres cosmológicos que habitam esses espaços, as narrativas míticas, as informaçóes que transmitem acerca do território e as formas de nomear as coisas - , pois tudo é classificado segundo protocolos específicos.

Nossa reflexão aqui procurou salientar, em parte, a transmissão de conhecimentos de povos que passaram por um brutal processo de colonização e, por isso, tiveram sua língua extinta, mas seus saberes permanecem vivos na documentaçáo histórica e em seus descendentes, como, por exemplo, os tupinambá da Serra do Padeiro. Buscou também analisar os critérios empregados pelos tupi para nomear a flora e a fauna, o que alguns pesquisadores chamam de etnotaxonomia.

Conhecedores profundos do clima e da diversidade ambiental das regióes que habitam, os povos indígenas (seus conhecimentos) podem ajudar na compreensão das mudanças climáticas, na perda da biodiversidade do planeta e na cura de doenças. É necessário, todavia, aproximar conhecedoras e conhecedores tradicionais e cientistas, fazer dialogar as diferentes formas de produção de conhecimentos (o que se produz nas comunidades tradicionais e nos centros de pesquisas e laboratórios) e difundir e valorizar a diversidade de protocolos de pesquisa e riqueza dos saberes indígenas, que são vivos e dinâmicos. De fato, essa seria uma grande transformação na nossa sociedade. Nhembojera, disso eu não tenho dúvidas.

\section{REFERÊNCIAS}

ALARCON, D. Dona Maria e o retorno dos encantados. In: BRUM, E. Racismo Ambiental. Disponível em: <https://acervo.racismoambiental.net.br $>$. Acesso em: 7 maio 2015 .

- O Retorno da Terra. As retomadas na aldeia tupinambá da Serra do Padeiro, Sul da Bahia. Dissertação (Mestrado em Ciências Sociais) - Instituto de Ciências Sociais, Universidade de Brasília, Brasília, 2013.

BARBOSA RODRIGUES, J. Mbaé kaá tapyiyeta enoyndua ou a botânica e a nomenclatura indígena. In: . A botânica: nomenclatura indígena e seringueiras. Rio de Janeiro: IBAMA/Jardim Botânico Rio de Janeiro, 1992. 
BENITES, S. Nhèê, reko porã rã: nhemboea oexakarẽ - Fundamento da pessoa guarani, nosso bem-estar futuro (educaçâo tradicional): o olhar distorcido da escola. 40f. Trabalho de Conclusão de Curso (Licenciatura Intercultural Indígena) Universidade Federal de Santa Catarina, Florianópolis, 2015.

BRASIL. Lei $n^{\circ}$ 11.645. Altera a Lei $n^{\circ}$ 9.394, de 20 de dezembro de 1996, modificada pela Lei $\mathrm{n}^{\circ} 10.639$, de 9 de janeiro de 2003, que estabelece as diretrizes e bases da educaçáo nacional, para incluir no currículo oficial da rede de ensino a obrigatoriedade da temática "História e Cultura Afro-Brasileira e Indígena”. Diário Oficial da República Federativa do Brasil, Brasília, 2008.

CARNEIRO DA CUNHA, M. Relaçóes e dissensóes entre saberes tradicionais e saber científico. In: . Culturas entre aspas e outros ensaios. São Paulo: Cosac Naify, 2009. p. 301-310.

D’ABBEVILLE, C. História da Missão dos Padres Capuchinhos na Ilha do Maranhão e terras circunvizinhas. Belo Horizonte: Itatiaia, São Paulo: Edusp, 1975.

D'ÉVREUX, Y. História das coisas mais memoráveis, ocorridas no Maranhão nos anos de 1613 e 1614. Rio de Janeiro: Betel / Fundação Darcy Ribeiro, 2009.

FAUSTO, C. Donos demais: maestria e domínio na Amazônia. Mana, Rio de Janeiro, v. 14, n. 2, p. 329-366, 2008. http://dx.doi.org/10.1590/S0104$\underline{93132008000200003}$

. Fragmentos de História e Cultura Tupinambá - Da etnologia como instrumento crítico de conhecimento crítico de conhecimento etno-histórico. In: CUNHA, M. (org). História dos Índios no Brasil. São Paulo: Companhia das Letras, 1992, p.381-96.

.FERNANDES, F. Aspectos da Educação na Sociedade Tupinambá. In: SCHADEN, E. (org.). Leituras de Etnologia Brasileira. São Paulo: Cia. Editora Nacional, 1976. p. 63-86.

FERREIRA, L.; NOELLI, F. João Barbosa Rodrigues: Precursor da Etnoclassificação na Arqueologia Amazônica. Amazônica, Belém, v. 1, n. 1, p. 68-95, 2009.

FREIRE, J. R. B. Cinco ideias equivocadas sobre o indio. Ensaios e Pesquisas em Educação e Cultura, Rio de Janeiro, v. 1, p. 3-23, 2016

. Rio Babel: a história das línguas no Amazonas. Rio de Janeiro: Atlântica, 2004.

IKPENG, K.; IKPENG, K.; TXICÃO, N. Marangmotxingmo Mïrang; Das crianças Ikpeng para o mundo. Recife: Vídeo nas Aldeias, 2001. 1 DVD. 35 min, son., color. 
LEMOS BARBOSA, A. Curso de tupi antigo: gramática, exercícios, textos. Rio de Janeiro: Livraria São José, 1956.

LÉRY, J. História de uma viagem feita à terra do Brasil, também chamada América. Trad. Maria Ignez D. Estrada. Rio de Janeiro: Betel, Fundaçáo Darcy Ribeiro, 2009.

LÉVI-STRAUSS, C. La pensée sauvage. Paris: Plon, 1962.

MONSERRAT, R. Guarani Mbya: aspectos de gramática da língua. Belo Horizonte: Fino Traço, 2017.

MONTEIRO, J. Tupis, tapuias e historiadores: estudos de história indígena e do indigenismo. Tese (Livre-Docência em Antropologia) - Departamento de Antropologia, Universidade Estadual de Campinas, Campinas, 2001.

OLIVEIRA, J. Entre plantas e palavras: modos de constituição de saberes entre os Wajäpi (AP). Tese (Doutorado em Antropologia Social) - Faculdade de Filosofia, Letras e Ciências Sociais. Universidade de São Paulo, São Paulo, 2012.

RODRIGUES, A. A contribuição linguística de Jean de Léry. In: LÉRY, J. História de uma viagem feita à terra do Brasil, também chamada América. Rio de Janeiro: Betel, Fundação Darcy Ribeiro, 2009.

SÁ, M. O botânico e o mecenas: João Barbosa Rodrigues e a ciência no Brasil na segunda metade do século XIX. História, Ciências, Saúde, Manguinhos, v. 8, p. 899-924, 2001. Disponível em: <http://dx.doi.org/10.1590/S010459702001000500006>. Acesso em: 23 jan. 2018.

SILVA, A. Mboapy nhanderuvixa tenondé guải oexara’ú vảe kuery Tekoa Sapukai py guá: kaxo yma guare, nheẽ ngatu, nhembojera [Três sonhadores do Tekoa Sapukai: história, oralidade, saberes]. Trabalho de Conclusão de Curso (Licenciatura em Educação do Campo) - Universidade Federal Rural do Rio de Janeiro, Seropédica, 2013.

SILVA, A. P. Narradores Tupinambá e etnosaberes nas crônicas francesas do Rio de Janeiro (1555-78) e do Maranhão (1612-15). Dissertação (Mestrado em Memória Social) - Centro de Ciências Humanas e Sociais, Universidade Federal do Estado do Rio de Janeiro, Rio de Janeiro, 2011.

SIMÕES, L. (coord.). Guia de Aves Mata Atlântica paulista: Serra do Mar e Serra de Paranapiacaba. São Paulo: WWF Brasil, 2010.

SZTUTMAN, R. O profeta e o principal: a ação política ameríndia e seus personagens. São Paulo: Edusp, 2012. 
THEVET, A. A Cosmografia Universal. Rio de Janeiro: Betel / Fundação Darcy Ribeiro, 2009.

VIVEIROS DE CASTRO, E. A natureza em pessoa: sobre outras práticas de conhecimento. In: RICARDO, C. A.; RICARDO, F. (orgs.). Povos Indigenas no Brasil: 2006/2010. São Paulo: Instituto Socioambiental, 2011. p. 69-72.

. Histórias Ameríndias. In: CARNEIRO DA CUNHA, M (org.). História dos Índios no Brasil. Novos Estudos Cebrap, São Paulo, v. 36, p. 22-33, 1993.

WEBER, I. Um copo de cultura: os Huni Kuin (Kaxinawá) do rio Humaitá e a escola. Rio Branco: EDFAC, 2006.

\section{NOTAS}

1. texto é inspirado na dissertação de mestrado intitulada Narradores tupinambá e etnosaberes nas crônicas francesas do Rio de Janeiro (1555-78) e do Maranhão (1612-15), defendida em março de 2011, no Programa de Pós-Graduação de Memória Social (PPGMS) da Universidade Federal do Estado do Rio de Janeiro (Unirio), sob orientaçáo do professor doutor José Ribamar Bessa Freire e coorientação de Ruth Maria Fonini Monserrat.

2. Emprego aqui o termo antigos tupi (ou apenas tupi), em detrimento do etnônimo tupinambá, para designar diferentes povos falantes de uma língua pertencente à família linguística tupi-guarani, habitantes na costa brasileira nos séculos XVI e XVII. Vale lembrar que a questáo dos etnônimos é bastante complexa e, conforme Viveiros de Castro (1993, p. 32), "fruto de uma incompreensão total da dinâmica étnica e política do socius ameríndio", bem como da "natureza relativa e relacional das categorias étnicas, políticas e sociais indígenas”. Para Monteiro (2001 p. 58), a projeção de unidade sobre povos foi um aspecto fundamental na formação de alianças e na determinação das políticas coloniais, servindo não apenas "como instrumento de dominação, como também de parâmetro para a sobrevivência étnica de grupos indígenas, balizando uma variedade de estratégias geralmente enfeixadas num dos polos do inadequado binômio acomodação/resistência” (MONTEIRO, 2001 p. 58). Baseando-se na documentação histórica, Fausto (1992 chama a atenção para o fato de os grupos tupi da costa brasileira, nos primeiros séculos da conquista, constituírem macroblocos populacionais e jamais um bloco homogêneo. Renato Sztutman (2012, p. 146), por sua vez, diz ser o etnônimo tupinambá vago ou problemático, uma vez que está relacionado à multiplicidade de povos tupi ocupantes da costa, além dos aliados dos franceses (no caso do Rio de Janeiro, eles eram denominados de tamoios).

3. Para as palavras e frases na língua guarani, segui as sugestôes de Ruth Monserrat (2017). Com relaçáo aos termos em língua tupinambá, procurei seguir as normas estabelecidas em Silva (2011). Optei, contudo, por manter as restauraçóes do padre Lemos Barbosa (1956) e de Rodrigues (2009) na crônica de Jean de Léry (2009). 
4. Lugares de reunióes masculinas, espécie de casas dos homens, em que os mais velhos transmitiam seus saberes, narravam mitos, dançavam e cantavam. Também se discutiam a vida cotidiana, a resoluçáo de problemas, entre outros assuntos.

5. Mbuy = varinha, espiga; $i b o t y=$ flor; $m i$ vem de mirim $=$ pequeno e por último $y u b a ́ a=$ amarelo, conforme Barbosa Rodrigues (1992, p. 38-39).

6. Uma versão dessa narrativa foi publicada no trabalho de conclusão de curso de Algemiro da Silva (2013).

7. Em palestra conferida no lançamento do filme Tupinambá: o retorno da terra, realizado no dia 5 de maio de 2015 pelo Programa de Estudos dos Povos Indígenas (Pró-Índio), na Universidade do Estado do Rio de Janeiro.

Recebido em 6 de fevereiro de 2019.

Aprovado em 9 setembro de 2019. 